\title{
Population structure of Thenus orientalis and T. indicus (Decapoda: Scyllaridae) in northeastern Australia
}

\author{
Clive M. Jones * \\ Northern Fisheries Centre, Queensland Department of Primary Industries, PO Box 5396, Cairns, Queensland 4870, Australia
}

\begin{abstract}
Bay lobsters of the genus Thenus are a valuable component of the incidental catch of the penaeid trawl fisheries of northern Australia. The 2 species present, Thenus indicus Leach, 1815 and Thenus orientalis (Lund, 1793), have mutually exclusive distributions. For each species, relative abundance, size and sex composition were measured monthly and related to physical characteristics including temperature, salinity, depth and sediment type. Both species populations were characterised by contagious distributions. Mean density of $T$ indicus was $1.78( \pm 0.15)$ lobsters ha ${ }^{-1}$, while that of $T$. orientalis was $2.02( \pm 0.13)$. In both populations, depth and sediment type were significantly correlated with abundance. $T$. indicus was most abundant in depths of 10 to $30 \mathrm{~m}$ and where sediments were characterised by a preponderance of fine sands and silt. In contrast, $T$ orientalis was most abundant in depths of 40 to $50 \mathrm{~m}$ and where sediments were composed primarily of medium-coarse sands of 0.25 to $1.00 \mathrm{~mm}$ particle size. In both species, mean size varied significantly throughout the year as a function of growth and recruitment. Male and female $T$. indicus were equally abundant, while male $T$. orientalis were significantly more abundant than females.
\end{abstract}

\section{INTRODUCTION}

Despite the extensive body of research concerning palinurid and nephropid lobsters (Cobb \& Phillips 1980), scyllarid lobsters, encompassing over 70 species, have been relatively poorly researched. Biological research has been limited and in most instances has dealt with species of some economic importance (Ben Tuvia 1968, Lyons 1970, Martins 1985).

Thenus is the most economically significant of the 7 scyllarid genera (Jones 1990). Species of this genus contribute to many of the demersal trawl fisheries which operate along the tropical coasts of the Indian Ocean and the Western Pacific region (Ben-Tuvia 1968, Prasad \& Tampi 1968, Isarankura 1971, Shindo 1973, Shirota \& Ratanachote 1973, Hossain 1974, Hossain et al. 1975, Mohan 1976, Saeger et al. 1976, Mutagyera 1979, Pauly 1979, Branford 1980, Ivanov \& Krylov 1980).

Within Australia, Thenus spp. are a significant catch component of coastal trawl fisheries which fish for

- Present address: Freshwater Fisheries \& Aquaculture Centre, Research Station, Walkamin, Queensland 4872, Australia penaeid shrimp species and in some localities, scallops (Amusium spp.). The catch records of these fisheries indicate the distribution of Thenus spp. extends along the sub-tropical and tropical coasts north of latitude $28^{\circ} \mathrm{S}$. Catches from the eastern Australian State of Queensland are the most significant.

Although the genus Thenus had been considered monospecific in Australia since the commercial potential of $T$. orientalis (Lund, 1793) was first recognised in Moreton Bay (Fison 1888), a second species has recently been distinguished (Jones 1988, 1990). A new species was to have been established (Jones 1990, Ito pers. comm.); however, investigations of type material and published manuscripts have led to the conclusion that $T$. indicus Leach, 1815, previously synonymised with $T$. orientalis, is a valid species. Neotypic material is now being gathered and a description prepared (Davie \& Jones unpubl.) which will demonstrate the morphological characteristics of the 2 species. In reference to Jones (1990), 'T. orientalis Type A' represents T. indicus, and ' $T$. orientalis Type $\mathrm{B}$ ' represents $T$. orientalis.

Both species are referred to commonly as bugs or bay lobsters. The history and development of the 
fishery for bay lobsters in Queensland, prior to the recognition of 2 species, were documented by Jones (1984).

Efforts to expand the trawl fisheries of coastal Queensland to achieve maximum utilisation of available benthic resources have effectively located and defined areas of greatest shrimp and bay lobster abundance. These areas are reasonably well demarcated and are recognised by the fishing industry as independent, localised fisheries. Each of these is characterised by location, season of optimum catch and shrimp species (Jones \& Derbyshire 1988). These localised fisheries are also characterised by the species and relative abundance of bay lobsters caught with the shrimp, effectively representing discrete populations of the species involved.

Discrete populations of Thenus indicus and T. orientalis were chosen for an examination of their population structure and biology. Population characteristics investigated in this study included: natural abundance and its spatial and temporal distribution, estimated from catch figures and catch per unit effort (CPUE) information, and size and sex composition.

\section{MATERIALS AND METHODS}

Population studies were made of the Wellesley Islands (Thenus indicus) and Townsville ( $T$. orientalis) populations of bay lobsters in Queensland (Fig. 1). A stratified random sampling technique was employed to sample lobsters in each population. Sampling stations were randomly located along transects selected to incorporate the variety of hydrographic features (predominantly depth and sediment characteristics) char-

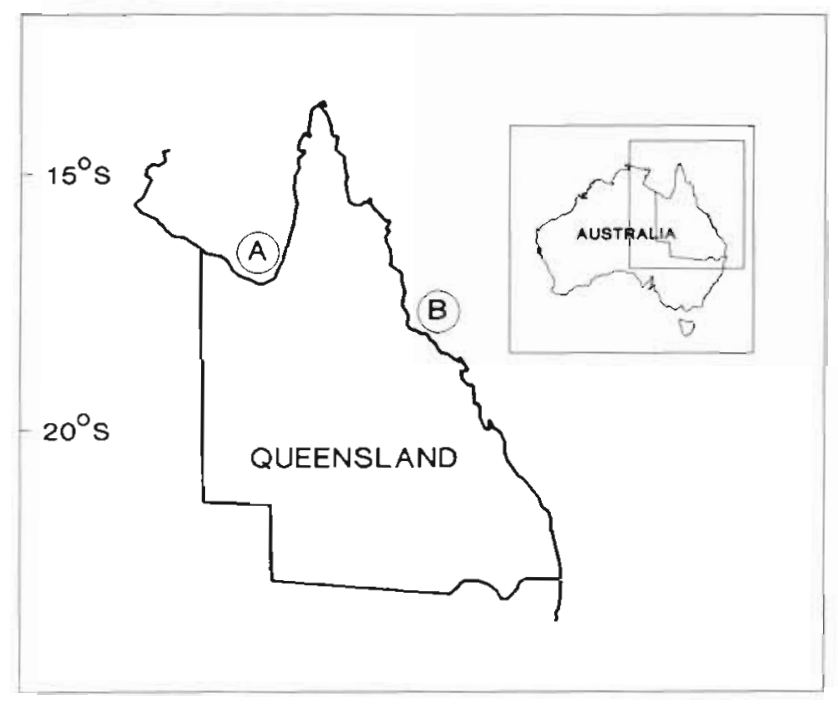

Fig. 1. Sampling locations for population studies of Thenus indicus ( $\mathrm{A}_{\text {; }}$ Wellesley Islands) and $T$. orientalis ( $\mathrm{B}$; Townsville) acteristic of the general area. In both studies all lobsters sampled were frozen and returned to the laboratory. For each lobster the following parameters were determined: sex, carapace length, reproductive stage (females only) and presence of eggs

Wellesley Islands study. This sampling program was initiated in January 1983. Sampling was carried out each month up to and including December 1983 at 40 stations in the vicinity of the Wellesley Islands in the southeastern Gulf of Carpentaria (Fig. 1). Bay lobsters were sampled with a double otter-trawl rig using 'Florida Flyer' nets (standard for the penaeid fishery), towed over the bottom for $30 \mathrm{~min}$, at a speed of $6 \mathrm{~km}$ $\mathrm{h}^{-1}$. All sampling took place between 19:00 and 05:00 h on consecutive nights, except at $\operatorname{Stn} 40$ where 60 min trawls were made every $2 \mathrm{~h}$ through a period of $24 \mathrm{~h}$. All samples were taken within $7 \mathrm{~d}$ of new moon.

Surface and bottom temperatures and salinities were recorded at the completion of each trawl using an Ekman conductivity/temperature meter. A sediment sample was collected for each station using a small $\left(0.04 \mathrm{~m}^{-2}\right)$ Smith/McIntyre grab. Particle size analyses were carried out at the laboratory.

Sediment from each station was characterised by the relative proportions of each of 7 particle size ranges, based on those of Folk (1968). Each sediment sample, approximately 200 g, was passed through a series of Endecott sieves under water pressure on an electric sieve shaker. The mud/silt fraction was decanted into a 11 beaker, flocculated by the addition of ammonia and filtered through Whatman 54 filter paper. All fractions were then dried in an oven at $85^{\circ} \mathrm{C}$ for $24 \mathrm{~h}$. Dried fractions were weighed and their relative proportion expressed as a percentage of total dry weight.

Townsville study. Sampling began in January 1985 and was repeated monthly through to December 1985 at 20 stations on the central eastern coast of Queensland (Fig. 1). Sampling involved the same equipment and procedure as described above. A 24 h sampling station was not included. Surface and bottom temperatures and salinities were similarly gathered as were sediment samples. Some lobsters selected for tagging were examined before being released. Lobsters were tagged for studies of growth and movement (Jones 1988).

Analyses. Data from stations not sampled due to adverse weather conditions in 2 or more months were not included in analyses. Twenty-eight stations were included in the Wellesley Islands database and 17 stations in the Townsville database. Spatial definition of the population of each species was made, giving due consideration to the known limits of commercial fishing activity (linked directly to the abundance of shrimps and/or bay lobsters) and the range of hydrographic features of the area. 
The spatial distribution of each population was defined by application of a model suggested by the index of dispersion, $I$ (Elliot 1977), calculated as the variance to mean ratio of catch frequency. Index of dispersion values approximating unity suggest a spatial distribution in agreement with the Poisson series. Departures from unity suggest regular $(I<1)$ or non-random $(I>1)$ distributions, and the significance of these departures was gauged by the Chi-square test

Because estimation of the negative binomial exponent $k$ was impractical due to small sample sizes, it was not possible to estimate confidence limits of means, nor to apply a suitable transformation (see Anscombe 1948, Thoni 1967, Elliot 1977) to enable parametric comparisons of means. Non-parametric methods were therefore employed.

A standardised catch (CPUE) was estimated for each station and expressed as the mean number of lobsters caught per hour trawled and per hectare trawled. Variability of catch between stations was measured by applying a Kruskal-Wallis 1-way analysis of variance (Siegel 1956). To account for the variability measured, correlations between catch and physical parameters (depth, sediment, temperature and salinity) were performed. Spearman's ranked correlation coefficients were calculated according to the methods of Siegel (1956).

Temporal variability in abundance, both seasonal and diel, was measured by the application of parametric analyses. Raw catch data were standardised by the number of hours fished and normalised by applying a $\log (x+1)$ transformation (Sokal \& Rohlf 1981). Analysis of variance and pairwise comparisons of means (Duncan's Multiple Range Test) were then employed.

Monthly frequency distributions of $4 \mathrm{~mm}$ carapace length classes were generated separately for male and female lobsters. The dissection of such distributions to describe the parameters of each component size class has historically been unreliable due to failure to reveal component size classes which have widely overlapping variances. Methods outlined by MacDonald \& Pitcher (1979) and Schnute \& Fournier (1980) have successfully overcome many of the shortcomings of previously used techniques, however, their underlying assumptions and prerequisite information precludes their effective use for crustacean size composition analysis. In particular, the inability to estimate the number of component size (age) classes of crustaceans, possible for fish by studying growth rings in scales or otoliths, confounds the procedures from their outset. Several attempts to dissect polymodal frequency distributions for Thenus indicus using the MacDonald/ Pitcher method (see MacDonald \& Pitcher 1979, MacDonald \& Green 1985, MacDonald 1987) and inputting different estimates of the number of component classes led to widely varying and clearly erroneous results. Visual 'Petersen' (1892) techniques were therefore employed.

While the use of a mean carapace length for a polymodal size frequency distribution can be confusing, it was used here to examine inter-species and intersexual differences through the year. Mean and $95 \%$ confidence intervals of carapace length for each species and sex were compared each month to test the hypothesis that the growth rate of males and females is different.

The sex ratio was investigated by examining the frequency distribution of the proportion of lobsters in each monthly sample which were male. Using the positive binomial model (Elliot 1977), means for the proportion of males in each month were calculated. Kruskal-Wallis analysis of variance was employed to measure the variability of the sex ratio.

\section{RESULTS}

Catch statistics for each species are presented in Tables $1 \& 2$

\section{Spatial distribution}

The spatial extent of the populations of Thenus indicus and $T$. orientalis was estimated to be approximately 12000 and $9000 \mathrm{~km}^{-2}$ respectively. The mean and variance of the catch frequency distribution for each month are presented in Tables 3 \& 4 . The variance to mean ratio, or index of dispersion $(I)$, is also given. The spatial distribution of both species, as gauged by the Chi-square values, was highly contagious in all months, with the exception of the March sample for $T$. orientalis. The lack of significance for this month was an artefact of the small number of samples $(n=4)$ and the distribution of lobsters was unlikely to be have been different from that of the other months sampled.

The relative abundance of lobsters as measured by the mean catch per hour over all sampling stations and months was $16.5( \pm 1.4)$ and $18.5( \pm 1.2)$ for Thenus indicus and $T$. orientalis respectively. Relative abundance as measured by mean catch per hectare was $1.78( \pm 0.15)$ and $2.02( \pm 0.13)$. The catch rate for $T$. orientalis was significantly greater $(p<0.001)$ than that of $T$. indicus. While the sampling method employed represents the 'state-of-the-art' commercial fishing method and is considered to be very efficient in the capture of penaeid shrimps and Thenus spp. lobsters, it is reasonable to assume that it would not have 
Table 1. Thenus indicus. Wellesley Islands survey (1983). Number caught for each sample. -: Stations not sampled

\begin{tabular}{|c|c|c|c|c|c|c|c|c|c|c|c|c|c|c|c|}
\hline Stn & Jan & Feb & Mar & Apr & May & Jun & Jul & Aug & Sep & Oct & Nov & Dec & Total & Ind. $\mathrm{h}^{-1}$ & Ind. ha \\
\hline 1 & 7 & 11 & 15 & 13 & - & - & 14 & 10 & 10 & - & 15 & 14 & 109 & 24.22 & 2.63 \\
\hline 2 & 8 & 5 & 8 & 4 & - & - & 4 & 8 & 3 & - & 51 & 32 & 123 & 27.33 & 2.97 \\
\hline 6 & 0 & 7 & 17 & 19 & - & - & - & 0 & 1 & - & 5 & 0 & 49 & 12.25 & 1.33 \\
\hline 10 & 0 & 0 & - & - & - & - & 0 & 0 & 2 & - & 3 & 7 & 12 & 3.43 & 0.37 \\
\hline 12 & 0 & 13 & 0 & - & - & - & 0 & 1 & 0 & - & 0 & 0 & 14 & 3.5 & 0.38 \\
\hline 13 & 0 & 0 & 3 & - & - & - & 0 & 0 & 2 & - & 2 & 2 & 9 & 2.25 & 0.24 \\
\hline 14 & 0 & 0 & 0 & - & - & - & 0 & 0 & 3 & - & 0 & 9 & 12 & 3.00 & 0.33 \\
\hline 15 & 0 & 10 & 8 & - & - & - & 4 & 13 & 20 & - & 11 & 14 & 80 & 20.00 & 2.17 \\
\hline 16 & 0 & 6 & 0 & - & - & - & 5 & 2 & 0 & - & 1 & 1 & 15 & 3.75 & 0.41 \\
\hline 17 & 0 & 27 & 29 & - & - & - & 1 & 0 & 1 & - & 3 & 3 & 64 & 16.00 & 1.74 \\
\hline 18 & 8 & 18 & 24 & - & - & - & - & 1 & 3 & - & 2 & - & 56 & 18.67 & 2.03 \\
\hline 21 & 12 & 0 & 3 & 1 & - & 2 & 0 & 1 & 1 & - & 2 & 1 & 23 & 4.60 & 0.50 \\
\hline 22 & 9 & 0 & 23 & 28 & - & 13 & 1 & 11 & 6 & - & 6 & 10 & 107 & 21.40 & 2.33 \\
\hline 23 & 11 & 1 & 29 & 26 & - & 5 & 0 & 4 & 3 & - & 0 & 6 & 85 & 17.00 & 1.85 \\
\hline 24 & 2 & 0 & 16 & 6 & - & 31 & 17 & 4 & 5 & - & 0 & 18 & 99 & 19.80 & 2.15 \\
\hline 25 & 9 & 0 & 4 & 3 & - & 11 & 6 & 8 & 18 & - & 6 & 0 & 65 & 13.00 & 1.41 \\
\hline 26 & - & 46 & 13 & 2 & 0 & 0 & 7 & 3 & 5 & - & 19 & 24 & 119 & 23.80 & 2.59 \\
\hline 27 & 0 & 16 & 4 & 28 & 4 & 5 & 0 & 3 & 2 & 3 & 6 & 2 & 73 & 12.17 & 1.32 \\
\hline 28 & 7 & 1 & 8 & 0 & 2 & 2 & 1 & 8 & 1 & 4 & 3 & 8 & 45 & 7.50 & 0.82 \\
\hline 29 & 11 & 13 & 21 & 12 & 29 & 4 & 0 & 3 & 8 & 25 & 9 & 24 & 159 & 26.50 & 2.88 \\
\hline 30 & 20 & 26 & - & - & 21 & 35 & 19 & 15 & 12 & 17 & 6 & 3 & 174 & 34.80 & 3.78 \\
\hline 31 & 5 & - & - & - & 1 & 0 & 28 & 7 & 6 & 7 & 11 & 23 & 88 & 19.56 & 2.13 \\
\hline 32 & 5 & - & - & - & 0 & 45 & 10 & 24 & 12 & 43 & 20 & 0 & 159 & 35.33 & 3.84 \\
\hline 33 & 14 & 2 & 17 & 3 & - & - & 0 & 0 & 20 & - & - & 0 & 56 & 14.00 & 1.52 \\
\hline 34 & - & 0 & 83 & 8 & - & - & 1 & 0 & 5 & - & - & 4 & 101 & 28.86 & 3.14 \\
\hline 35 & - & 0 & 33 & 13 & - & - & 0 & 0 & 2 & - & - & 8 & 56 & 16.00 & 1.74 \\
\hline 36 & - & 0 & 7 & 7 & - & - & - & 0 & 0 & - & - & 20 & 34 & 11.33 & 1.23 \\
\hline 40 & 127 & 16 & 1118 & - & 144 & 242 & 168 & 110 & 25 & 31 & - & 38 & 2019 & 16.97 & 1.84 \\
\hline Total & 255 & 218 & 1483 & 173 & 201 & 395 & 286 & 236 & 176 & 130 & 181 & 271 & $4005^{\mathrm{a}}$ & & \\
\hline Ind. $\mathrm{h}^{-1}$ & 10.85 & 8.9 & 63.11 & 21.63 & 12.97 & 23.24 & 11.92 & 9.25 & 6.90 & 8.67 & 15.74 & 18.07 & \multirow{2}{*}{\multicolumn{2}{|c|}{$16.79^{b}$}} & \\
\hline Ind. ha ${ }^{-1}$ & 1.18 & 0.97 & 6.86 & 2.35 & 1.41 & 2.53 & 1.30 & 1.01 & 0.75 & 0.94 & 1.71 & 1.96 & & & $1.83^{c}$ \\
\hline
\end{tabular}

Table 2. Thenus orientalis. Townsville survey (1985). Number caught for each sample. -: Stations not sampled

\begin{tabular}{|c|c|c|c|c|c|c|c|c|c|c|c|c|c|c|c|}
\hline Stn & Jan & Feb & Mar & Apr & May & Jun & Jul & Aug & Sep & Oct & Nov & Dec & Total & Ind. $\mathrm{h}^{-1}$ & Ind. ha ${ }^{-1}$ \\
\hline 3 & 9 & 10 & 7 & 4 & 11 & 6 & 10 & 9 & 4 & 7 & 15 & 4 & 96 & 24.22 & 2.63 \\
\hline 4 & 13 & 26 & 8 & 4 & 14 & 0 & 3 & 5 & 5 & 4 & 3 & 3 & 88 & 27.33 & 2.97 \\
\hline 5 & 5 & - & 5 & 5 & 1 & 3 & 3 & 0 & 0 & 0 & 0 & 1 & 23 & 12.25 & 1.33 \\
\hline 6 & 5 & 1 & 0 & 1 & 2 & 0 & 1 & 0 & 0 & 2 & 0 & 0 & 12 & 3.43 & 0.37 \\
\hline 7 & 7 & 8 & - & 12 & 24 & 5 & 8 & 3 & 4 & 5 & 5 & 4 & 85 & 3.5 & 0.38 \\
\hline 8 & 3 & 1 & - & 1 & 1 & 1 & 2 & 1 & 2 & 1 & 5 & 1 & 19 & 2.25 & 0.24 \\
\hline 9 & 4 & 8 & - & 4 & 15 & 5 & 6 & 12 & 11 & 12 & 11 & 9 & 97 & 3.00 & 0.33 \\
\hline 10 & 13 & 6 & - & 7 & 7 & 2 & 5 & 4 & 9 & 0 & 4 & 6 & 63 & 20.00 & 2.17 \\
\hline 11 & 4 & - & - & 12 & 8 & 2 & 7 & 14 & 15 & 7 & 9 & 6 & 84 & 3.75 & 0.41 \\
\hline 12 & 26 & 4 & - & 28 & 39 & 11 & 20 & 26 & 29 & 48 & 43 & 20 & 294 & 16.00 & 1.74 \\
\hline 13 & 9 & 16 & - & 3 & 9 & 14 & 11 & 11 & 10 & 10 & 13 & 22 & 128 & 18.67 & 2.03 \\
\hline 14 & 11 & 12 & - & 7 & 7 & 10 & 9 & 11 & 15 & 13 & 12 & 11 & 118 & 4.60 & 0.50 \\
\hline 16 & 18 & - & - & 13 & 11 & 13 & 11 & 6 & 20 & 35 & 17 & 27 & 171 & 21.40 & 2.33 \\
\hline 17 & 5 & - & - & 15 & 20 & 15 & 20 & 9 & 15 & 21 & 9 & 10 & 139 & 17.00 & 1.85 \\
\hline 18 & 14 & - & - & - & 25 & 13 & 10 & 3 & 5 & 16 & 8 & 8 & 102 & 19.80 & 2.15 \\
\hline 19 & 10 & - & - & - & 22 & 5 & 10 & 5 & 9 & 11 & 12 & 6 & 90 & 13.00 & 1.41 \\
\hline 20 & 9 & - & - & - & 5 & 9 & 6 & 9 & 11 & 2 & 10 & 7 & 68 & 23.80 & 2.59 \\
\hline Total & 165 & 92 & 20 & 116 & 221 & 114 & 142 & 128 & 164 & 194 & 176 & 145 & $1677^{d}$ & & \\
\hline Ind. $\mathrm{h}^{-1}$ & 19.41 & 18.40 & 10.00 & 16.57 & 26.00 & 13.41 & 16.71 & 15.06 & 19.29 & 22.82 & 20.71 & 17.06 & & $18.53^{b}$ & \\
\hline Ind. $\mathrm{ha}^{-1}$ & 2.11 & 2.00 & 1.09 & 1.80 & 2.83 & 1.46 & 1.82 & 1.64 & 2.10 & 2.48 & 2.25 & 1.85 & & & $2.01^{c}$ \\
\hline
\end{tabular}


Table 3. Thenus indicus. Catch frequency distribution statistics for the Wellesley Islands population, 1983. Based on raw counts of lobsters per trawl (sampling unit). ' $p<0.05$. Means accompanied by the same letter are not significantly different $(p<0.05)$

\begin{tabular}{|c|c|c|c|c|c|c|c|}
\hline Month & $\begin{array}{l}\text { Sampling } \\
\text { units }(n)\end{array}$ & $\begin{array}{c}\text { Mean } \\
\qquad(\vec{x})\end{array}$ & $\begin{array}{l}\text { Variance } \\
\text { (s) }\end{array}$ & $\begin{array}{c}\text { Index of } \\
\text { dispersion }(I)\end{array}$ & $\begin{array}{l}\text { Chi- } \\
\text { square }\end{array}$ & $\mathrm{p}$ & Distribution \\
\hline Jan & 23 & $5.57^{a b c}$ & 32.35 & 5.81 & 127.77 & $\cdot$ & Contagious \\
\hline Feb & 25 & $7.56^{\mathrm{abc}}$ & 129.17 & 17.09 & 410.06 & $\cdot$ & Contagious \\
\hline Mar & 23 & $15.87 \mathrm{~cd}$ & 315.12 & 19.86 & 436.84 & $\cdot$ & Contagious \\
\hline Apr & 16 & $10.81 \mathrm{bcd}$ & 93.63 & 8.66 & 129.92 & $\cdot$ & Contagious \\
\hline May & 7 & $8.14^{\mathrm{ahc}}$ & 139.81 & 17.18 & 103.05 & $\cdot$ & Contagious \\
\hline Jun & 12 & $12.75 \mathrm{~cd}$ & 238.57 & 18.71 & 205.83 & $\cdot$ & Contagious \\
\hline Jul & 24 & $4.92^{\mathrm{a}}$ & 56.34 & 11.45 & 263.38 & $\cdot$ & Contagious \\
\hline Aug & 27 & $4.63^{\mathrm{ab}}$ & 35.17 & 7.60 & 197.50 & $\cdot$ & Contagious \\
\hline Sep & 27 & $5.59^{\mathrm{abc}}$ & 35.94 & 6.42 & 167.16 & $\cdot$ & Contagious \\
\hline Oct & 6 & $16.50 \mathrm{~d}$ & 240.70 & 14.59 & 72.94 & $\cdot$ & Contagious \\
\hline Nov & 23 & $7.87^{\mathrm{abcd}}$ & 122.48 & 15.56 & 342.38 & $\cdot$ & Contagious \\
\hline $\mathrm{Dec}$ & 26 & $8.96^{\mathrm{abcd}}$ & 86.84 & 9.69 & 242.30 & $\cdot$ & Contagious \\
\hline
\end{tabular}

Table 4. Thenus orientalis. Catch frequency distribution statistics for the Townsville population, 1985. Based on raw counts of lobsters per trawl (sampling unit). $p<0.05$; ns: not significant. Means accompanied by the same letter are not significantly different $(p<0.05)$

\begin{tabular}{|c|c|c|c|c|c|c|c|}
\hline Month & $\begin{array}{l}\text { Sampling } \\
\text { units (n) }\end{array}$ & $\begin{array}{l}\text { Mean } \\
(\bar{x})\end{array}$ & $\begin{array}{l}\text { Variance } \\
\text { (s) }\end{array}$ & $\begin{array}{c}\text { Index of } \\
\text { dispersion }(I)\end{array}$ & $\begin{array}{l}\text { Chi- } \\
\text { square }\end{array}$ & $p$ & Distribution \\
\hline $\operatorname{Jan}$ & 17 & $9.71^{\mathrm{ab}}$ & 35.10 & 3.61 & 57.84 & - & Contagious \\
\hline Feb & 10 & $9.20^{\mathrm{ab}}$ & 56.84 & 6.18 & 55.60 & $\cdot$ & Contagious \\
\hline Маг & 4 & $5.00^{\mathrm{a}}$ & 12.67 & 2.53 & 7.60 & ns & \\
\hline Apr & 14 & $8.29^{\mathrm{ab}}$ & 52.84 & 6.37 & 82.86 & $\cdot$ & Contagious \\
\hline May & 17 & $13.00^{b}$ & 104.38 & 8.03 & 128.47 & $\cdot$ & Contagious \\
\hline Jun & 17 & $6.71^{\mathrm{ab}}$ & 26.60 & 3.96 & 63.43 & $\cdot$ & Contagious \\
\hline Jul & 17 & $8.35^{\mathrm{ab}}$ & 29.37 & 3.52 & 56.28 & $\cdot$ & Contagious \\
\hline Aug & 17 & $7.53^{\mathrm{ab}}$ & 41.14 & 5.46 & 87.42 & $\cdot$ & Contagious \\
\hline Sep & 17 & $9.65^{\mathrm{ab}}$ & 57.74 & 5.95 & 95.73 & - & Contagious \\
\hline Oct & 17 & $11.41^{\mathrm{ab}}$ & 168.38 & 14.76 & 236.12 & - & Contagious \\
\hline Nov & 17 & $10.35^{a b}$ & 94.99 & 9.18 & 146.84 & • & Contagious \\
\hline $\mathrm{Dec}$ & 17 & $8.53^{a b}$ & 58.89 & 6.90 & 110.46 & $\cdot$ & Contagious \\
\hline
\end{tabular}

Correlation coefficients $\left(r_{s}\right)$ calculated for catch per hectare of each station, and the percentage of each of 7 sediment grades, indicated significant relationships between abundance and the nature of the sediment. For Thenus indicus strong relationships were evident for 0.125 $0.25 \mathrm{~mm}$ particle size $(\mathrm{p}<0.05)$. and $0.25-0.5 \mathrm{~mm}(\mathrm{p}<0.08)$. The distribution of catch per trawl sample in relation to the percentage of these 2 sediment grades and in relation to the finest grade, $<0.063 \mathrm{~mm}$, are given in Fig. 2 .

Although the correlation of catch with the sediment class $<0.063 \mathrm{~mm}$ was not significant, it was included because of its significance in sediment preference experimentation of laboratory held lobsters (Jones 1988). Fig. 2 indicates that the proportion of several sediment particle size classes contributes to the relative abundance of Thenus indicus such that sediments characterised by having 40 to $60 \%$ of particles in the range 0.125 $0.25 \mathrm{~mm}$ and 20 to $40 \%$ of particles in the ranges of $<0.063$ and $0.25-0.5 \mathrm{~mm}$ are most preferred.

In contrast, correlations between catch and the percentage of each sediment grade for Thenus orientalis revealed captured every lobster in the sampling area. Actual abundance of lobsters is therefore possibly higher than the catch figures suggest. Nevertheless, the estimates presented indicate that the both populations sampled represented a minimum of around 2 million individuals.

Analysis of variance (Kruskal-Wallis) of catch per hour between stations (all months) indicated significant variability $(\mathrm{p}<0.001)$, supporting the preliminary finding that lobsters were contagiously distributed in both populations. Moreover, it suggested that the characteristics of the sampling stations were differentially suited to the habitation of these species. Characteristics most likely to influence lobster abundance are the nature of sediment and the water depth Temperature and salinity were homogeneous amongst stations in both studies and therefore not responsible for the variability. quite different associations. The 2 finest sediment grades, $<0.063$ and $0.063-0.125 \mathrm{~mm}$, were highly negatively correlated $(\mathrm{p}<0.01)$ with catch, while the percentage of the $0.25-0.5 \mathrm{~mm}$ grade was highly positively correlated. The relative abundance of $T$. orientalis as measured by mean catch per trawl sample in relation to the relative abundance of 4 sediment particle size classes is presented in Fig. 3. This illustrates a preference for sediments characterised by a preponderance of medium to coarse sands

Correlations between catch and depth also indicated strong but disparate relationships for each species. Spearman rank correlation statistics are given in Table 5. The catch frequency distribution in relation to depth for each species is presented in Fig. 4. This indicates that depths of between 10 and $30 \mathrm{~m}$ support the greatest abundance of Thenus indicus, while T. orientalis is most abundant in depths of 40 to $50 \mathrm{~m}$. 


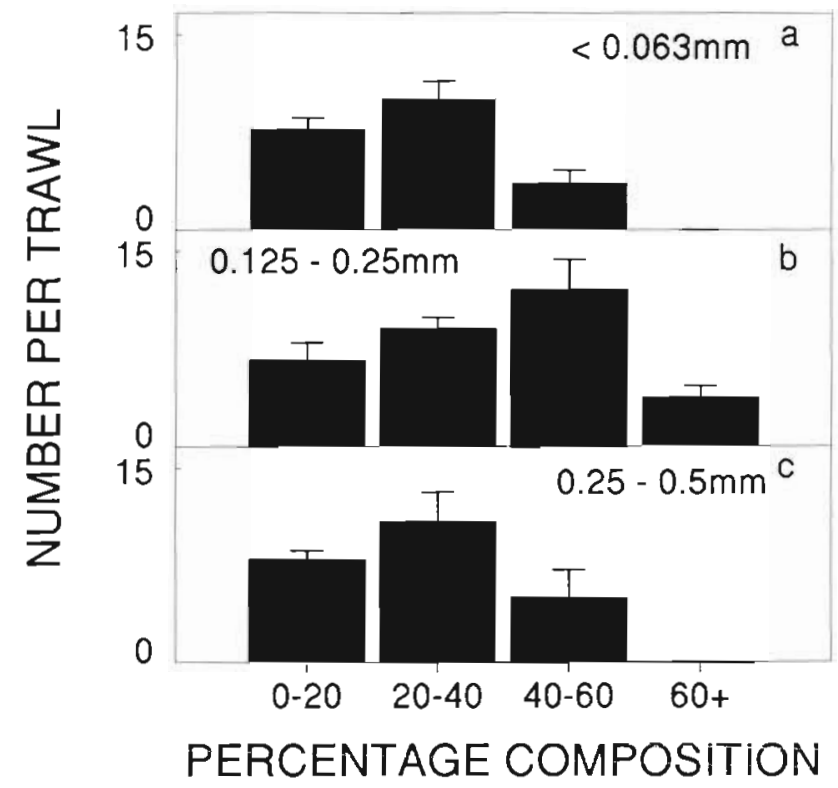

Fig. 2. Thenus indicus. Distribution of mean catch per 30 min trawl in relation to the percentage composition of sediment for (a) $<0.063$, (b) $0.125-0.25$ and (c) $0.25-0.5 \mathrm{~mm}$ particle size classes. Error bars represent $1 \mathrm{SE}$

\section{Temporal distribution}

A comparison of index of dispersion values for each month (Table 3 ) suggested considerable variability in the degree of aggregation of Thenus indicus through

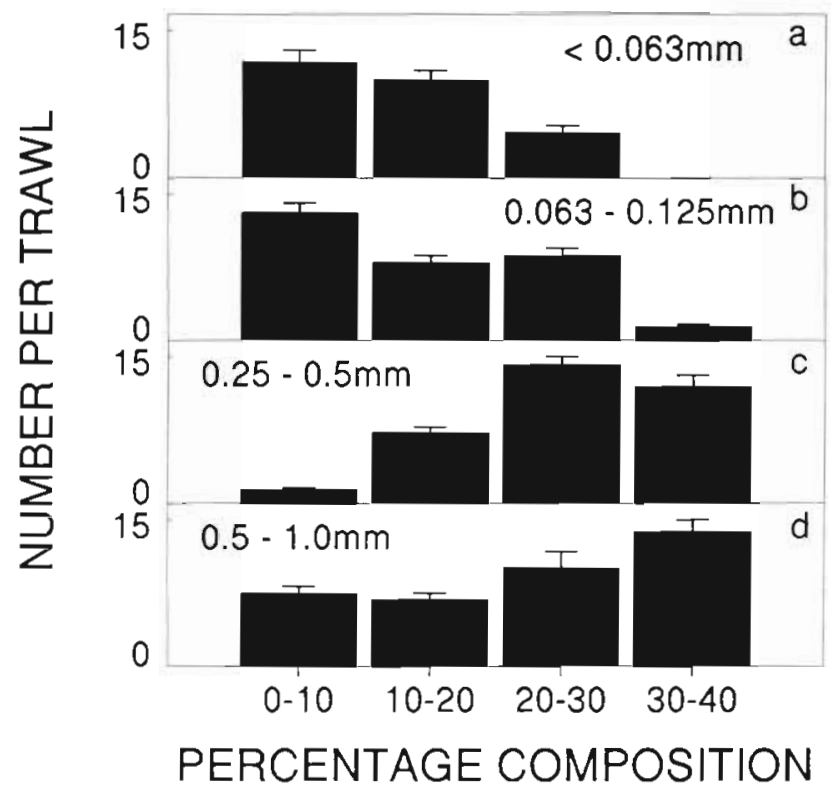

Fig. 3. Thenus orientalis. Distribution of mean catch per 30 min trawl in relation to the percentage composition of sediment for (a) $<0.063$, (b) $0.063-0.125$, (c) $0.25-0.5$ and (d) 0.5 to $1.0 \mathrm{~mm}$ particle size classes. Error bars represent $1 \mathrm{SE}$ time. This was supported by analysis of variance of catch which indicated significant variability $(p<0.01)$ through the year. Although the data suggest 2 periods of increased abundance, the first from February to June and the second in October, this was not fully consistent with pairwise comparisons (Table 3).

In contrast, index of dispersion values for Thenus orientalis for each month (Table 4) were reasonably uniform suggesting little variability in distribution through time. This was confirmed by an analysis of variance which indicated insignificant variability $(p=0.767)$ between months.

Diel variability in catch of Thenus indicus was also examined by sampling through $24 \mathrm{~h}$, each month at 1 sampling station. A 2-way ANOVA (month and timeof-day) indicated significant variability of abundance through the year $(\mathrm{p}<0.01)$, as demonstrated above, but no significant variability with time of day (Table 6). Aithough catches appeared to be greater during the night hours for most months, catches during the daylight hours were occasionally high, and in some months, particularly July and October, were greater than those of the night hours. The absence of a consistent diel pattern from month to month can be attributed in part to the non-random spatial distribution of lobsters. Although 24 h sampling was conducted at 1 sampling station, each trawl covered a different area of sea floor.

By pooling the catch information over the year and examining the mean catch per trawl in each of 4 time phases (Fig. 5), it was apparent that catches were greater during hours of darkness, however, the differences between each phase were found to be not significant $(p<0.05)$.

Diel variability in catch of Thenus orientalis was not specifically investigated during the Townsville survey, however, two 24 h samples of trawl catch were taken within the survey area. Although the sample sizes were extremely small $(n<25)$ and unlikely to be truly representative, it is worthy of note that the bulk of each sample was caught during daylight hours.

\section{Size composition}

Monthly size frequency distributions for each species are presented in Figs. $6 \& 7$. The Thenus

Table 5. Thenus indicus and $T$ orientalis. Spearman rank correlation statistics for catch in relation to depth $(z)$

\begin{tabular}{|lrrc|}
\hline Species & $\mathrm{r}_{s}$ & $z$ & $\mathrm{p}$ \\
\hline T. indicus & 0.28 & 1.41 & 0.08 \\
T. orientalis & -0.46 & -1.86 & 0.05 \\
\hline
\end{tabular}




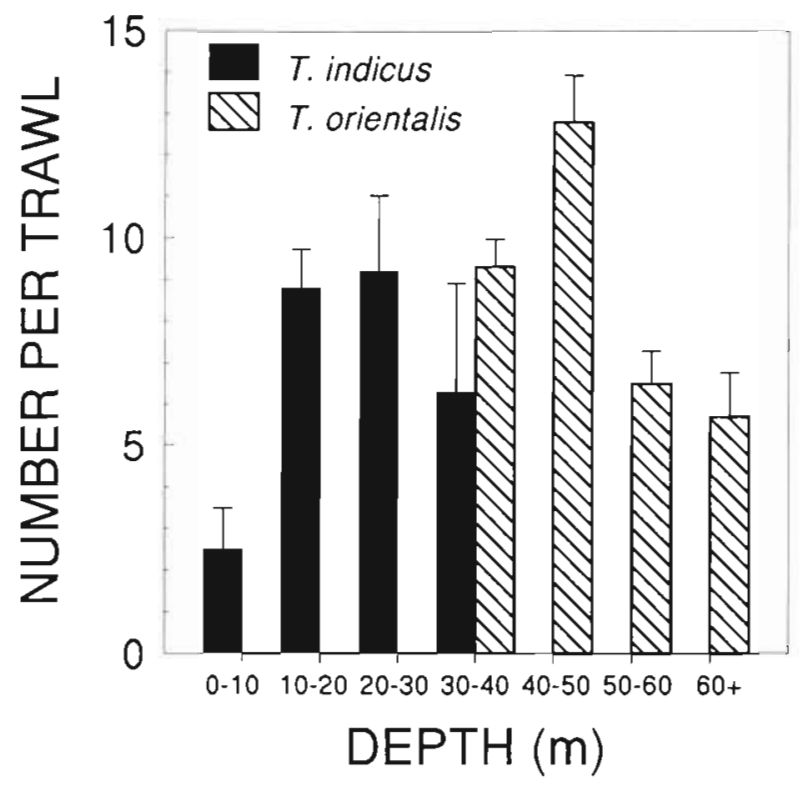

Fig. 4. Mean catch of Thenus indicus and $T$ orientalis per 30 min trawl for each of 4 depth categories. Error bars represent $1 \mathrm{SE}$

indicus (Fig. 6) population consisted of 2 size classes in January, the first presumably a $0+$ year class (mean size approximately $30 \mathrm{~mm}$ carapace length), and the second possibly representing several overlapping year classes $(1+)$. The $0+$ year class mode, evident for both males and females, remained distinct in February and March, but began to merge with the $1+$ classes in April and May, and became indistinguishable from the rest of the population by June. Progression of the $0+$ year class mode from January onwards and its amalgamation with the $1+$ year classes by June indicates reduction in growth rate of the larger (older) individuals. Examination of the growth of $T$. indicus (Jones 1988) suggested that the $1+$ year class seen here may consist of 3 or more overlapping size classes, each representing a successive year class.

A mode evident for both males and females in December's distribution, and representing individuals with a mean carapace length of approximately 20 to $25 \mathrm{~mm}$, represents a major recruitment of juveniles

Table 6. Thenus indicus. Analysis of variance (2-way) statistics for catch through time (month of year and time phase of dayj. $\cdots p<0.001$

\begin{tabular}{|lrrrc|}
\hline Factor & SS & df & MS & \multicolumn{1}{c|}{$F_{\mathrm{s}}$} \\
\hline Catch per month & 58.79 & 9 & 6.53 & $11.49 \cdots$ \\
Catch per time phase & 3.15 & 3 & 1.05 & 1.85 \\
Error & 15.35 & 27 & 0.57 & \\
Total & 77.30 & 39 & & \\
\hline
\end{tabular}

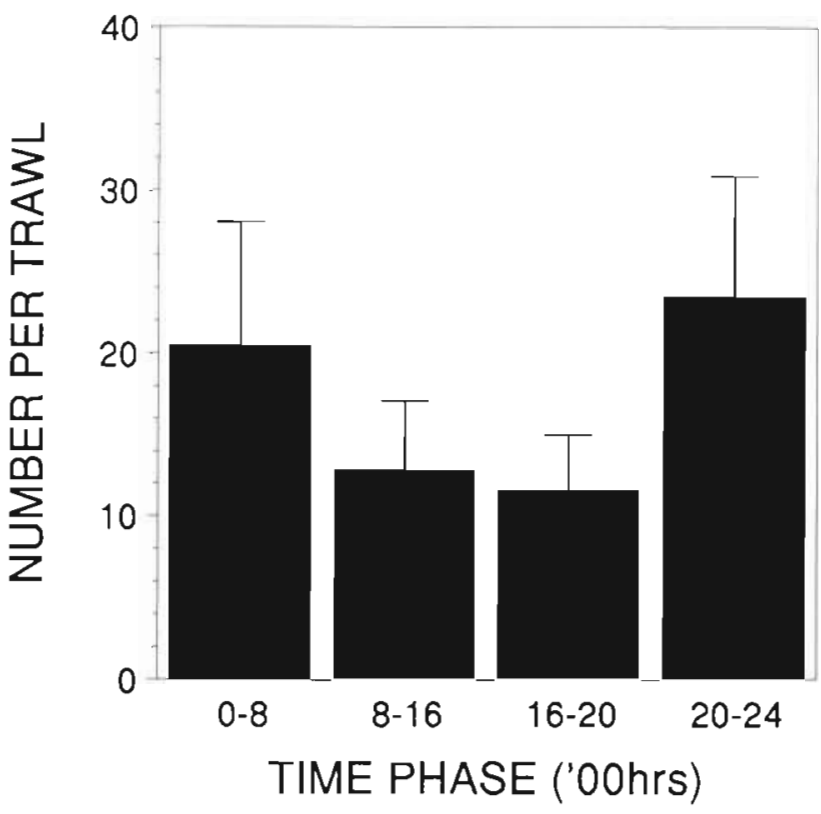

Fig. 5. Thenus indicus. Mean catch per $1 \mathrm{~h}$ trawl in each of 4 time phases. Error bars represent $1 \mathrm{SE}$

to the population. This mode is equivalent to the $0+$ year class mode evident in January. Further recruitment, at a much lower level, was apparent throughout the latter half of the year. Although the $0+$ year class was quite distinct for several months from January, the indefinite nature of the larger size classes may in part be attributable to this protracted low level recruitment.

Monthly size frequency distributions for Thenus orientalis are presented in Fig. 7. A mode corresponding to juvenile $0+$ year class individuals was first discernible in January for each sex. This mode represented lobsters with a mean carapace length of around $26 \mathrm{~mm}$ and constituting approximately $20 \%$ of the population at that time. These lobsters represent the major recruitment pulse to the population for the year. Individually distinct $1+$ year classes are not discernible within the remaining portion of this distribution, which for convenience was termed the secondary mode.

The $0+$ year class mode remained distinct for each sex in February and March, but became less discernible in April and May as it merged with larger individuals to form what was termed the primary mode. This primary mode represents lobsters with a mean carapace length of between 45 and $50 \mathrm{~mm}$, and remained evident from May through to November. Its static nature from May to August is attributable to a balance between growth of individuals, protracted low-level recruitment during the first 6 months of the year and natural mortality. After 

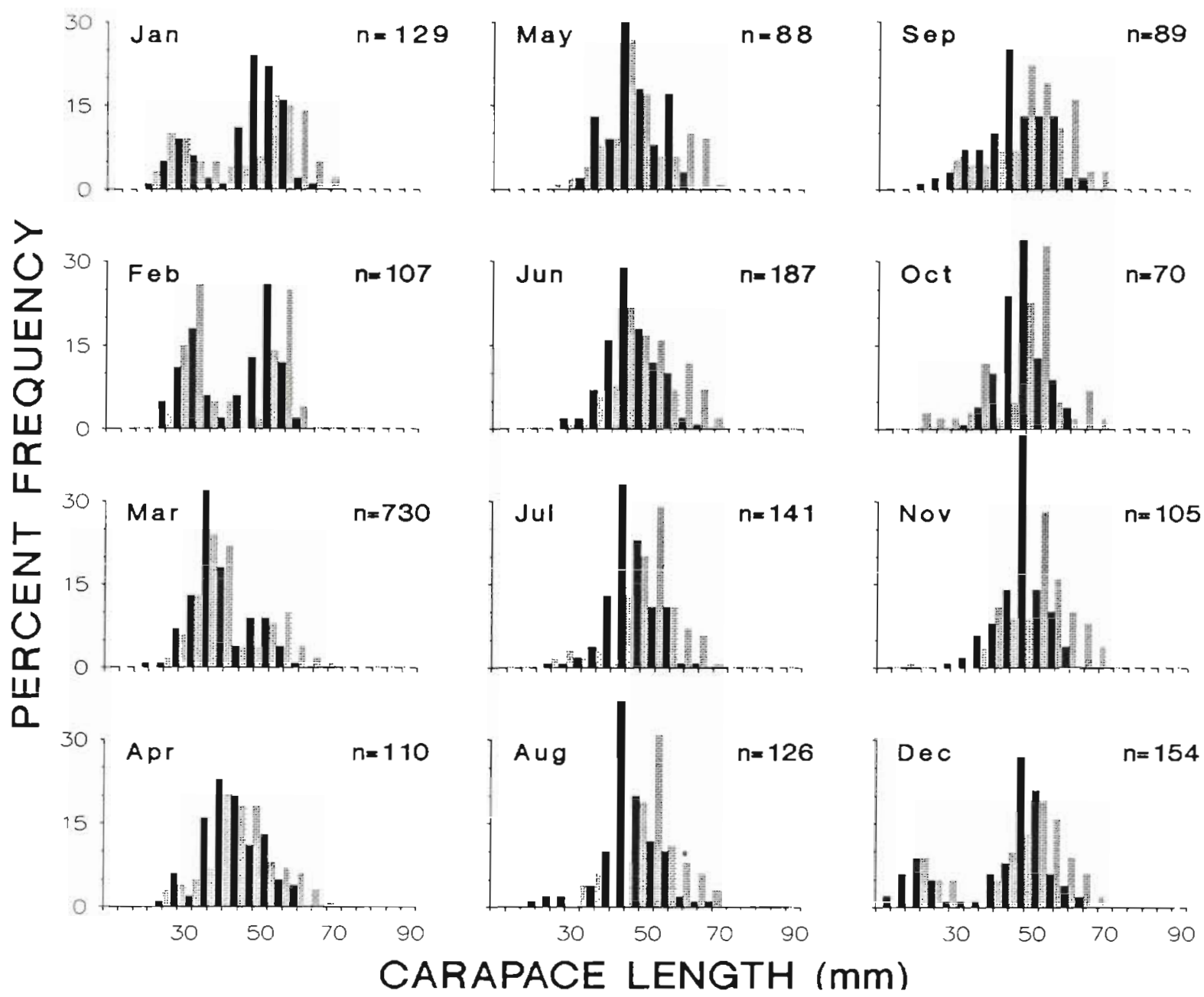

Fig. 6. Thenus indicus. Size frequency distributions (carapace length, $\mathrm{mm}$ ) of males (

and females (1) for each month of 1983

August when recruitment had ceased, this mode progressed through to December at which time it represented lobsters with a mean carapace length of approximately $58 \mathrm{~mm}$. Although sampling was discontinued after December, this mode would have progressed to become the secondary mode, as for January 1985. This secondary mode represents several year classes and is characterised by relatively slow growth. Growth estimates for Thenus orientalis (Jones 1988) indicate that 3 or more year classes may be represented.

Although the smallest individuals recruited in December for Thenus indicus and in January for $T$ orientalis, the proportion of new recruits in the population increased to a maximum in March for both species, as evidenced by the progressive decline in mean carapace length over this period (Fig. 8).

Mean carapace length varied significantly $(p<0.01)$ throughout the year for both sexes and both species
(Fig. 8). While mean carapace length varied similarly for each sex throughout the year for Thenus orientalis, there were significant deviations between sexes for $T$. indicus, particularly from June through December. This deviation was such that female carapace length was significantly greater than that of males. A similar deviation occurred for $T$. orientalis in December only.

\section{Sex ratio}

Sex ratio within the Thenus indicus population remained constant at $1: 1(p=0.21)$ throughout the year, while male $T$. orientalis were significantly more prevalent than females (Chi-square, $p<0.05$ ). There was no significant variability $(\mathrm{p}=0.58)$ in this prevalence throughout the year with the mean proportion of males remaining constant at 0.57 . 

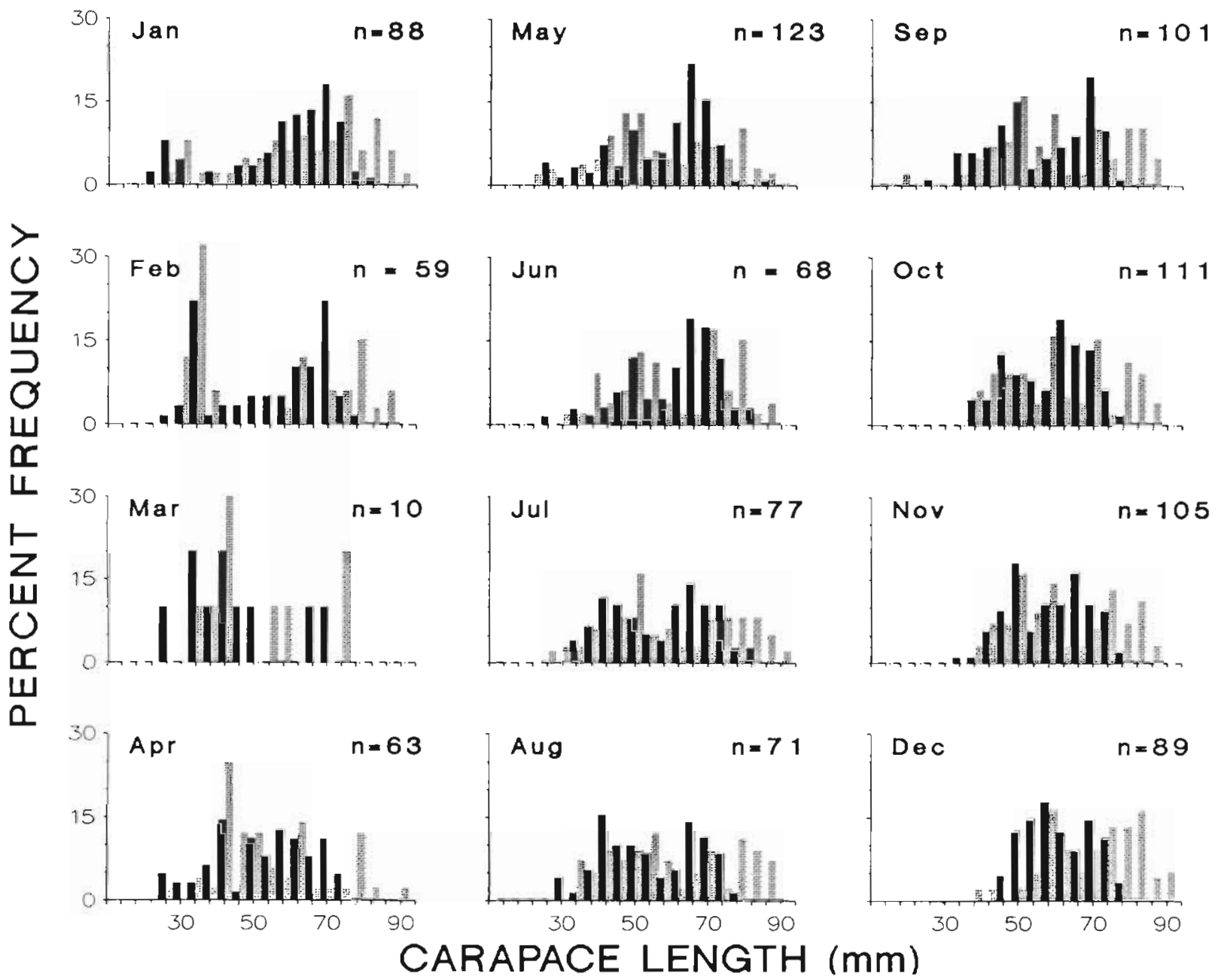

Fig. 7 Thenus orientalis. Size frequency distributions (carapace length, mm) of males (

\section{DISCUSSION}

Localised distribution patterns within populations of lobsters have received little attention in the literature. A major contributing factor is likely to be the complexity of habitats, particularly for palinurids, and the difficulty of describing (mathematically) the distribution of individuals. Nevertheless, in situ observations of Panulirus argus (Herrnkind et al. 1975) have indicated that the distribution of palinurids can be non-random, as found here for Thenus spp. Nonrandom distributions have also been described for other scyllarid species (Lyons 1970), however, little attempt has been made to investigate the contributing factors.

Non-random or contagious distributions are typical of many benthic species (Bliss 1953, Taylor 1953, Saila \& Gaucher 1966, Elliot 1977), and are usually attributed to the influence of environmental factors. The degree of aggregation and/or dispersion of a species in a particular area is likely to be a reflection of the habitat preference of the species and the relative availability of that habitat type. Consequently, contagious distribution patterns are highly variable, both within and between species. The direct application of a single mathematical model to such distributions is therefore difficult, although the negative-binomial model is considered to be the best approximation (Saila \& Gaucher 1966).

Although both Thenus species were contagiously distributed, the spatial distribution of $T$. indicus was more aggregated than that of $T$. orientalis as evidenced by the greater magnitude of indices of dispersion ( $I$ ). This difference is attributable to lower mean catch values resulting from increased frequency of zero counts, and higher variance in catch for $T$. indicus. For both species, the distribution is a reflection of reasonably specific habitat preference, and the differ- 

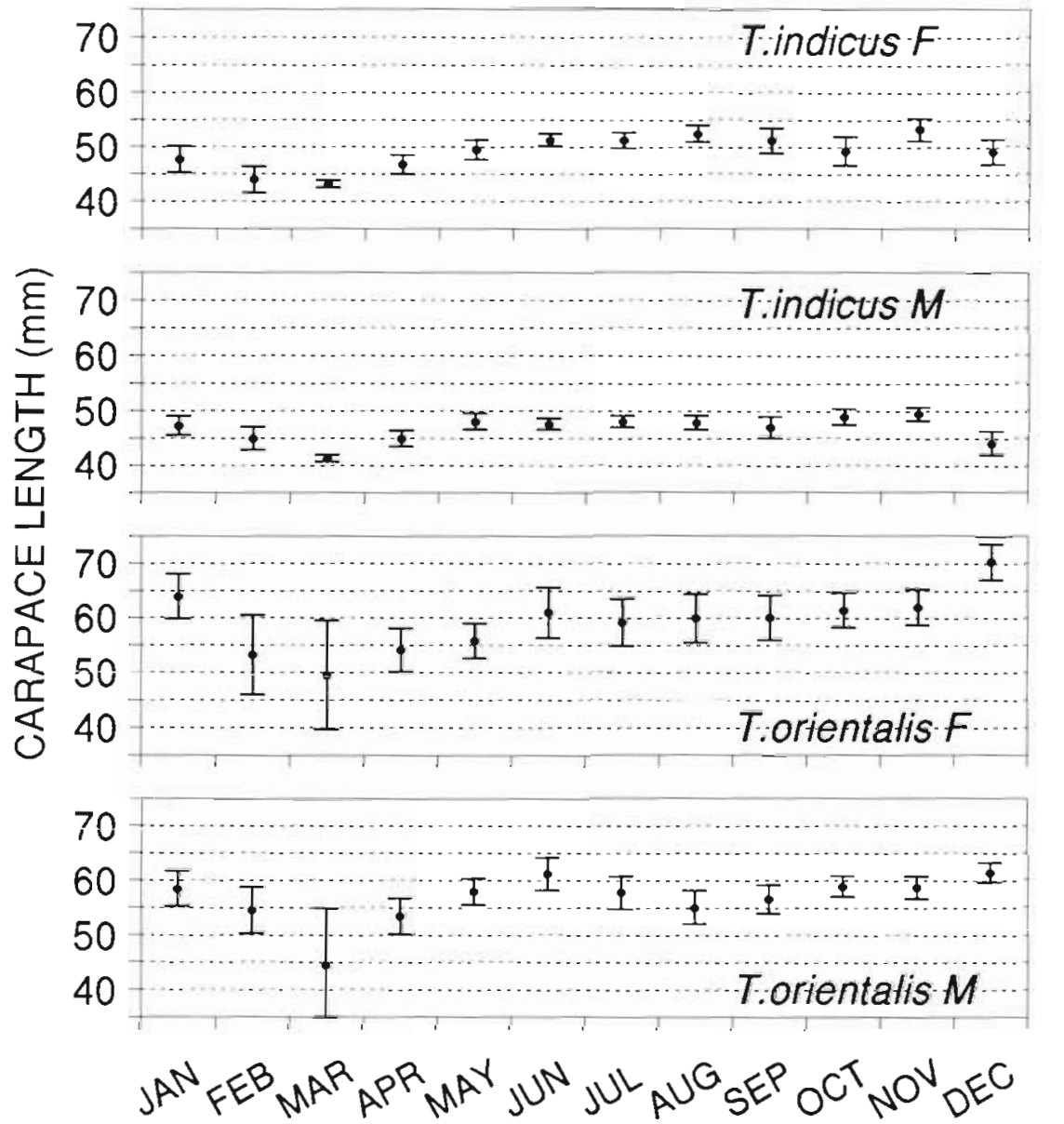

Fig. 8. Thenus indicus and $T$. onientalis. Mean carapace length (mm) of males (M) and females ( $F$ ) for each month of 1983 and 1985 respectively. Error bars represent $95 \% \mathrm{CI}$

ences in degree of aggregation may be attributable to differences in the relative availability of preferred habitat types. The results supported hypotheses based on the experience of fishermen, that $T$. indicus was an inhabitant of relatively shallow waters, between 10 and $30 \mathrm{~m}$ and of areas characterised by fine soft sediments, and that $T$. orientalis was typically abundant in depths of between 30 and $60 \mathrm{~m}$ in areas characterised by coarser sandy sediments.

Behaviourally, the habitat associations found suggest that Thenus orientalis avoid fine sediments and prefer medium grade sediments. This hypothesis is clearly supported by the nature of the distribution of catch rates in relation to the percentage composition of sediments (Fig. 3). Sediment preference experimentation of laboratory-held lobsters (Jones 1988) indicated a preference, out of 7 sediment grades offered, for the grade characterised by particles of $0.5-1.0 \mathrm{~mm}$. Although the correlation between the percentage of this sediment grade and catch was not highly significant $(p<0.13)$, it was strong. Fig. $3 d$ shows that higher percentages of this sediment grade do support greater catches. These results indicate that the relative proportions of several sediment particle size classes are important, and highlight the utility of field verification of laboratory results.

Although the habitat types preferred by each species are clearly different, they are both sedimentary in nature and typically support a variety of penaeid shrimp species, upon which are based commercial fisheries. Jones \& Derbyshire (1988) indicated the shrimp species normally associated with each of the Thenus species. While both species of Thenus appear io be equally susceptible to the 'otter-trawl' fishing gear, which is employed in all the shrimp fisheries of northern Australia, it is possible that $T$. orientalis populations extend into close proximity to coral reefs where such a fishing method could not be used. Personal observation of dredge samples in such 'near-reef' areas indicates the abundance of $T$. orientalis to be quite low. This habitat could be considered peripheral to the main population distribution based on the open seabed between reefs. For the purposes of this study, the sampling method employed and the areas sampled are likely to have provided truly representative samples of the population of $T$. orientalis.

Although the sampling techniques have varied widely, the documented catch densities of many tropical palinurids (Peacock 1974, Kanciruk 1980) are in the same order of magnitude ( 0 to $10 \mathrm{ind} . \mathrm{ha}^{-1}$ ) as those for Thenus spp. In contrast, the density of temperate lobsters inhabiting uniform depositional substrata (Nephrops spp.) or more complex rock/sediment substrata (Homarus spp.) (Cooper \& Uzmann 1980) is often much greater, in the order of hundreds or thousands of individuals per hectare. Such latitudinal differences are typical of many faunal groups and can be attributed to differences in environmental productivity (Morgan 1980) and complexity. Seasonal variability in abundance of Thenus spp. was similar to that reported for other tropical lobster species (Lyons et al. 1981).

The significance of the correlation between depth and abundance may in part be attributable to interrelationships between sediment characteristics and 
depth. Although the spatial distribution of Thenus indicus abundance bears strong independent relationships both with sediment characteristics and with depth, the nature of the relationships is influenced by significant interaction between them $(p<0.01)$. Other more subtly variable physical characteristics such as sediment porosity, particle shape, content and nature of organic matter, and water quality may also be of importance, particularly at a localised distributional level. Such fine-level characteristics are likely to be of greater significance than gross topographical features, given the flat and featureless nature of the typical Thenus spp. environment.

Biological factors may also influence spatial distribution. Although there was no evidence of behaviourally stimulated aggregation for reproductive or migratory purposes, the influence of other species' (prey, predator, competitor) distributions on that of Thenus spp. are likely to be significant. Whether these sort of factors contribute to the differential distributions of the 2 species is not apparent from the results of this study. The sampling regime for both the Wellesley Islands and Townsville areas indicated no spatial overlap of populations of the 2 species, i.e. they have allopatric distributions. As such, competitive interaction between them which may explain their discrete distributions is not evident. Nevertheless, the operation of such a mechanism cannot be discounted.

The significant variability in catch (abundance) between months for Thenus indicus was not evident for T. orientalis. It was postulated that the peaks in catch of $T$. indicus corresponded to periods of recruitment. Although the $T$. orientalis population experienced similar recruitment pulses, the increase in catch due to new recruits was not significant relative to catch levels throughout the year. Seasonally variable commercial fishing effort may have contributed to variability in abundance. The level of commercial fishing effort and its seasonality within the 2 populations studied is likely to have been significantly different.

Diel patterns in catch were extremely variable for both species. Catch levels appeared to bear no relation to patterns of activity as described from aquarium observations of both species (Jones, 1988). This suggests that the susceptibility of Thenus spp. to the trawling method employed was independent of behaviour

The influence of diel patterns of behaviour on susceptibility to fishing method and therefore catch ('catchability'), has been documented for several benthic species (e.g. Kubo \& Ishiwata 1964, Farmer 1974. Main \& Sangster 1985). Diel activity patterns of both Thenus orientalis and $T$. indicus observed in the laboratory (Jones 1988) indicated that these species remain inactive and buried in the sediment during daylight hours. It was hypothesised, therefore, that the catchability of these lobsters in relation to the trawling method employed is greater during the periods of peak activity, in the evening and early morning, than during the day.

However, the absence of any direct association between the time of day (and therefore activity pattern) and catch rates as established in this study suggests that inactive (buried) lobsters are equally susceptible to being caught as those which are active. This can be attributed to the effectiveness of the 'tickler-chain' on the fishing gear. This device consists of a heavy steel chain attached below and slightly in advance of the bottom edge of the fishing net. This chain scours the top few centimetres of the sediment, its purpose to disturb the benthic fauna so that it will jump into the path of the net following. Because Thenus spp. bury themselves within the top few centimetres of sediment, the tickler-chain causes them to be equally catchable whether active and on top of the sediment, or buried beneath it.

Further examination of diel variability in catch is justified, particularly in view of the implications to commercial fishing methods.

The size structure of the Thenus spp. populations examined was characterised by the distinctness of the $0+$ year class and the broad overlap of subsequent year classes. This pattern is similar to other tropical lobsters and to many tropical species in general, which display protracted recruitment and variable growth rates (Lyons et al. 1981).

Thenus orientalis were significantly larger than $T$. indicus as evidenced by comparisons of mean carapace length between the 2 species ( $t$-test, $p<0.001)$ for each sex. The difference in the means indicates that $T$. orientalis are between 27 and $28 \%$ larger (in carapace length) than $T$. indicus. This represents a difference in mean total weight of approximately $113 \%$ in males and $90 \%$ in females between the species.

The most conspicuous features of carapace length variability between months, and common to both species, were the progressive decline in mean carapace length from January to March and its subsequent increase up to June. This similarity was reflected in the modal year class structures of each species which show strong resemblance, particularly in the form and progression of the $0+$ year class mode. The timing of recruitment, which corresponds to the first appearance of this mode, was different for each species, however this difference cannot be considered significant in the context of the monthly sampling strategy employed. A major recruitment of post-larvae, borne from a peak spawning period, is likely to be of reasonably short duration, and its timing strongly influenced by prevailing hydrographic conditions. A short period of 
sampling once per month could possibly miss all or part of this recruitment.

Because the results are from surveys that were separate in space and time, they are only sufficient to indicate that major recruitment occurs in midsummer in both species. The low level recruitment which occurred outside of the midsummer pulse for both species was irregular in its timing and magnitude. Given the persistent but low frequency of egg-bearing females throughout the year (Jones 1988) it seems likely that low-level recruitment was more continuous than the results indicated and that seasonally differential mortality of larvae and/or juveniles may have occurred. The delicate nature of the phyllosoma larvae and their reliance on suitable hydrographic conditions for successful recruitment to the adult habitat would reasonably explain such irregularity. The vagaries of recruitment of lobsters are well documented (see Phillips \& Sastry 1980).

The sexual discrepancy in mean carapace length evident in some months, and particularly for Thenus indicus, such that females were larger than males may in part be attributable to a faster growth rate in females. However, it is also possible that the difference is not representative of the population because of differential catchability resulting from behavioural changes associated with reproduction. Such a discrepancy has been documented for Nephrops spp. (Chapman 1980).

Although sex ratio was reasonably stable within each population examined, sex ratios documented in the literature for Thenus orientalis (sic) from other localities (Shirota \& Ratanachote 1973, Branford 1980) indicate wide geographic variability. As indicated above and as documented for other lobster species (Farmer 1975, Chapman 1980), this may in part be attributable to differential catchability.

Many lobster species have wide geographic ranges which represent several distinct populations, separated to a varying extent by physical barriers and often genetically heterogeneous. These species sub-units can differ not only in geographic location, but in biological characteristics including growth rate, mortality and spawning/recruitment timing (Morgan 1980, Saila \& Marchessault 1980)

The populations of the 2 Thenus species studied here represent such species sub-units. They have been recognised as discrete species on the basis of morphology and tissue chemistry (Jones 1990). Within the geographic range of the Queensland coastline, several sub-populations of each species have been recognised (Jones 1990) and several more are likely to exist in other parts of the Indo-West Pacific region. Whether these sub-populations are genetically discrete is yet to be determined, however, it is important to recognise that the population characteristics described in this study may differ for other populations.

Amongst the larger lobster species which support commercial fishing, Thenus is the only genus which inhabits tropical, sedimentary (soft) substrata. Although this has led to several specialised morphological and behavioural adaptations (Jones 1988, 1990), the population characteristics of this genus are in many respects similar to those of other lobsters, particularly tropical palinurid species.

Acknowledgements. I am grateful to Dr Jack Greenwood for his supervision of the research and critical appraisal of the manuscript. I thank all the staff of the Northern Fisheries Centre for their assistance and particularly Gerry Goeden, Kurt Derbyshire and Malcolm Pearce. This research was part of a Doctorate study conducted under the co-supervision of the University of Queensland Zoology Department and the Queensland Department of Primary Industries. Fisheries Services. Funding assistance was provided through the Australian Marine Sciences and Technologies Grants Scheme.

\section{LITERATURE CITED}

Anscombe, F. J (1948). The transformation of Poisson, binomial and negative binomial data. Biometrika 35: $246-254$

Ben-Tuvia, A. (1968). Report on the fisheries investigations of the Israel South Red Sea expedition, 1962. Rep. No. 33. Bull. Sea Fish. Res. Stn Haifa 52: 21-55

Bliss, C. I. (1953). Fitting the negative binomial distribution to biological data. Biometrics 9: 176-200

Branford, J. R. (1980). Notes on the scyllarid lobster Thenus orientalis (Lund, 1793) off the Tokar Delta (Red Sea). Crustaceana 38(2): 221-224

Chapman, C. J. (1980). Ecology of juvenile and adult Nephrops. In: Cobb, J. S., Phillips, B. F. (eds.) The biology and management of lobsters, Vol. 2, Ecology and management, Chap. 4. Academic Press, New York, p. 143-178

Cobb, J. S., Phillips, B. F. (eds.) (1980). The biology and management of lobsters. Vol. 1, Physiology and behaviour. Vol. 2. Ecology and management. Academic Press, New York

Cooper, R. A., Uzmann, J. R. (1980). Ecology of juvenile and adult Homarus. In: Cobb, J. S., Phillips, B. F. (eds.) The biology and management of lobsters, Vol. 2, Ecology and management, Chap. 3. Academic Press, New York, p. $97-142$

Elliott, J. M. (1977). Some methods for the statistical analysis of samples of benthic invertebrates. Scient. Publs Freshwat. biol. Ass. U.K. 25

Farmer, A. S. D. (1974). Field assessment of diurnal activity in the Irish Sea populations of the Norway lobster Nephrops norvegicus. Estuar. coast. mar. Sci. 2: $37-48$

Farmer, A. S. D. (1975) Synopsis of biological data on the Norway lobster. F.A.O. Fish. Synopsis 112

Fison, C. S. (1888). Reports on the oyster and other fisheries within the ports of Moreton Bay and Maryborough. Queensland Department of Ports and Harbours, Brisbane

Folk, R. L. (1968). Petrology of sedimentary rocks. Hemphills, Austin 
Herrnkind, W. F., Vanderwalker, J. A., Barr, L. (1975). Population dynamics, ecology and behaviour of spiny lobsters, Panulirus argus, of St. John, U.S. Virgin Islands. IV. Habitation, patterns of movement and general behaviour. Nat. Hist. Mus. Los Ang. Cty Sci. Bull. 20: 31-46

Hossain, M. A. (1974). On the squat lobster, Thenus orientalis (Lund) off Visakhaptnam (Bay of Bengal). Curr. Sci. 44(5): $161-162$

Hossain, M. A., Shyamasundari, K., Hanumantha, R. K. (1975) On the landing of sand lobster, Thenus orientalis (Lund). Seafood Export J. 7(4): 1-6

lsarankura, A. P. (1971). Assessment of stocks of demersal fish off the west coasts of Thailand and Malaysia. IOFC/DEV/ 71/20. F.A.O., Rome

Ivanov, B. G., Krylov, V. V. (1980). Length-weight relationships in some common prawns and lobsters (Macrura, Natantia and Reptantia) from the Western Indian Ocean. Crustaceana 38(3): 279-289

Jones, C. M. (1984). Development of the bay lobster fishery in Queensland. Aust. Fish. 43(9): 19-21

Jones, C. M. (1988). The biology and behaviour of bay lobsters, Thenus spp. (Decapoda: Scyllaridae) in northern Queensland, Australia. Ph.D. thesis, University of Queensland, St. Lucia

Jones, C. M. (1990). Morphological characteristics of bay lobsters, Thenus Leach species (Decapoda, Scyllaridae), from north-eastern Australia. Crustaceana 59(3): 265-275

Jones, C. M., Derbyshire, K. J. (1988). Sampling the demersal fauna from a commercial penaeid prawn fishery off the central Queensland coast. Mem. Qd Mus. 25(2): $403-415$

Kanciruk, P. (1980). Ecology of juvenile and adult Palinuridae (spiny lobsters). In: Cobb, J. S., Phillips, B. F. (eds.) The biology and management of lobsters, Vol. 2, Ecology and management, Chap. 2. Academic Press, New York, p. $59-96$

Kubo, I., Ishiwata, N. (1964). On the relationship between activity of Japanese spiny lobster and underwater light intensity. Bull. Jap. Soc. scient. Fish. 30(11): 884-888

Lyons, W. G. (1970). Scyllarid lobsters (Crustacea: Decapoda). Mem. 'Hourglass' Cruises 1(4): 1-74

Lyons, W. G., Barber, D. G., Foster, S. M., Kennedy, F. S. Jr, Milano, G. R. (1981). The spiny lobster, Panulirus argus, in the middle and upper Florida Keys: population structure, seasonal dynamics and reproduction. Fla mar. Res. Publs 38

MacDonald, P. D. M. (1987). Analysis of length frequency distributions. In: Summerfelt, R. C., Hall, G. E. (eds.) Age and growth of fish. Iowa State University Press, Ames, p. $371-384$

MacDonald, P. D. M., Green, P. E. J. (1985). User's guide to program MIX: an interactive program for fitting mixtures of distributions. Icthus Data Systems, Hamilton, Ontario

MacDonald, P. D. M., Pitcher, T J. (1979). Age-groups from size frequency data: a versatile and efficient method of analysing distribution mixtures. J. Fish. Res. Bd Can. 36: $987-1001$

Main, J., Sangster, G. I. (1985). The behaviour of the Norway lobster, Nephrops norvegicus (L.), during trawling. Scott. Fish. Res. Rep. 34

Martins, H. R. (1985). Biological studies of the exploited stock of the Mediterranean locust lobster Scyllarides latus (Latreille, 1803) (Decapoda: Scyllaridae) in the Azores. J. Crust. Biol. 5(2): 294-305
Mohan, R. S. Lal. (1976). Some aspects of fishery and biology of the mud lobster, Thenus orientalis from Mandapam. Proc. Ind. Sci. Congr. 1976, 3rd Ses. (abstract only)

Morgan, G. R. (1980). Population dynamics of spiny lobsters. In: Cobb, J. S., Phillips, B. F. (eds.) The biology and management of lobsters, Vol. 2, Ecology and management. Chap. 5. Academic Press, New York, p. 189-217

Mutagyera, W. B. (1979). On Thenus orientalis and Metanephrops andamanicus (Macrura, Scyllaridae and Nephropidae) off Kenya coast. East Afr. agric. For. J. 45(2) $142-145$

Pauly, D. (1979). Theory and management of tropical multispecies stocks. A review, with emphasis on the Southeast Asian demersal fisheries. ICLARM Studies and Reviews No. 1, Int. Center for Living Aquatic Res. Mgmt, Manila

Peacock, N. A. (1974). A study of the spiny lobster fishery of Antigua and Barbuda. Gulf Caribb. Fish. Inst., Univ. Miami, Proc. 26: 117-130

Petersen, C. G. J. (1892). Fiskensbiologiske forhold; Holboek Fjord, 1890-91 Beret. Danske Biol. Sta., 1890(91) 1 $121-183$

Phillips, B. F., Sastry, A. N. (1980). Larval ecology. In: Cobb, J. S., Phillips, B. F. (eds.) The biology and management of lobsters, Vol. 2, Ecology and management, Chap. 1. Academic Press, New York, p. 11-57

Prasad, R. R., Tampi, P. R. S. (1968). On the distribution of palinurid and scyllarid lobsters in the Indian Ocean. J. mar. Biol. Ass. India 10(1): 78-87

Saeger, J., Martosubroto, P., Pauly, D. (1976). First report of the Indonesian-German demersal fisheries project. Results of a trawl survey in the Sunda Shelf area. Jakarta Marine Fisheries Research Reports/Contrib. Demer. Fish. Proj. No. 1

Saila, S. B., Gaucher, T. A. (1966). Estimation of the sampling distribution and numerical abundance of some mollusks in a Rhode Island salt pond. Proc. Natn. Shellfish. Ass. 56: $73-80$

Saila, S. B., Marchessault, G. (1980). Population dynamics of clawed lobsters. In: Cobb, J. S., Phillips, B. F. (eds.) The biology and management of lobsters, Vol. 2, Ecology and management, Chap. 6. Academic Press, New York, p. $219-241$

Schnute, J., Fournier, D. (1980). A new approach to lengthfrequency analysis: growth structure. Can. J. Fish. Aquat. Sci. 37(9): 1337-1351

Shindo, S. (1973). General review of the trawl fishery and the demersal fish stocks of the South China Sea. F.A.O. Fish. tech. Pap. No. 120

Shirota, A., Ratanachote, A. (1973). Preliminary observation on the distribution and catch of the shovel-nosed lobster, Thenus orientalis Lund in South China Sea. Southeast Asian Fisheries Development Centre, Bangkok

Siegel, S. (1956). Nonparametric statistics for the behavioral sciences. International student edition. McGraw-Hill Kogakusha Ltd, Tokyo

Sokal, R. R., Rohlf, F. J. (1981). Biometry. The principles and practice of statistics in biological research. 2nd edn. W. H. Freeman and Co., San Francisco

Taylor, C. C. (1953). Nature and variability in trawl catches. U.S. Fish. Wildl. Serv. Fish. Bull. 54(83): 145-166

Thoni, H. (1967). Transformations of variables used in the analysis of experimental and observational data. A review. Technical Report No. 7. Statistical Laboratory, Iowa State University, Ames

Manuscript first received: April 12, 1991

Revised version accepted: May 3, 1993 